\title{
INTERNET FOR RETAIL -A GAME CHANGER FOR RETAIL INDUSTRY
}

\author{
Dr. K C Prashanth ${ }^{1}$ \\ Department of Business Administration, Vijayanagara Sri Krishnadevaraya University, Ballari, \\ Karnataka \\ Dr. Veena $\mathbf{M}^{2}$ \\ Department of Commerce, Vijayanagara Sri Krishnadevaraya University, Ballari, Karnataka
}

Article DOI: https://doi.org/10.36713/epra4194

\section{INTRODUCTION}

In the past, the main focus for retailers was that of mass production and sales. These were times when retailers were in the advantage seat as consumer demands were exceeding the actual supply. However, today's market is different story. The focus of businesses today has shifted to create a great customer experience and give value to the customers, not just selling them products and services. Technology played a crucial role as it has made it easier for customers to be well informed. Hyken(2016) argues that customers today are smarter, hence their expectations are higher than even before. He also added that since large companies have "educated customers of what a great customer service looks like, now customers are have come to expect it" (Hyken, 2016). Lashbrooke(2016) also has his views on this subject as he states that since consumer demands are ever increasing, without a doubt it is creating a shift on the was businesses are conducted. He added that today's customer needs are “forcing change upon businesses' out-dated customer services and procedures" (Lashbrooke, 2016).

Chang, Dong and Sun (2014)defined customer experience as 'the customers' perceptual and emotional responses brought about in the process of interaction with companies' products, services and other elements". Every experience is becoming a digital experience as things that are perceived as being 'ordinary' are becoming more intelligent and smart (Gregory, 2015). Hsu and Lin (2016) defined smart objects as a "physical embodiment with communication functionality, possessing a unique identifier, some basic computing capabilities and a way to detect physical phenomena and to activate actions having an effect on physical reality". The increasing number of smart objects that are connected to the internet have gave rise to the concept of Internet of Things (Hsu and Lin, 2016).Gregory (2015) argues that while the concept of Inter of Things may be seen like a dream and "it is becoming a reality faster than most of us can comprehend". Retailers that fail to realise such fact will open the doors for their competitors, ending up in losing the competitive advantage in such diverse and complex market. Gierej (2017) argues that Internet of Things is causing companies to redesign their products and services in order to survive in today's market.

\section{DEFINING INTERNET OF THINGS}

It was a British entrepreneur, Kevin Asthon, who back in 1999 came up with the concept of Internet of Things (Vyas, Bhatt and Jha, 2016). Lopez Research LLC (2013) clearly defines Internet of Things as "a system where items in the physical world and sensors within or attached to these items, are connected to the Internet via wireless and wired Internet connections". Aleksandrovičs, Filičevs and Kampars (2016) states that Internet of Things comes in different forms - ranging from a number of simple sensors that can be found easily in a room, to a more complex and global structure. Patel and Patel(2016) added that items are connected over public or private Internet Protocol networks and such items include data that is "regularly collected, analysed and used to initiate action, providing a wealth of intelligence for planning, management and decision making”. 


\section{EPRA International Journal of Research and Development (IJRD)}

Without a doubt, Internet of Things has revolutionized the retail industry and the way service and value is delivered to customers. Till now, there are already a large number of connected devices and IoT services, and the market for these services is continuously growing (Hsu and Lin, 2016). In their research, Krotov (2017) states that market research companies have estimated a rise in the number of connected devices; from 16 billion connected devices in 2014 to 50 billion in 2020. Such rise will result in trillion of dollars in revenue for retail industries. However, since the number of connected devices is large, there is the need to further regulate issues such as data protection (Weber, 2015). Issues such as privacy will be further discussed in the below sections.

\section{TODAY'S RETAIL INDUSTRY}

Nowadays, the retail scenario involves "physical spaces where consumers engage in commerce" in which consumers are able to buy goods or services(Martin, 2016). One may have various types of retail stores, such of which include the grocery shops which fall under the traditional shops though also different types of stores may be considered as part of the retail industry such as showrooms(Martin, 2016). Therefore the retail industry may be considered as a volatile industry, prone to changes and evolutions in line with different technologies which have been created and those which might be created and progressed in the future. The rapid increase in complexity of internet, such as Internet of Things, has revolutionised the retail industry. Sorescu et al. (2011)discusses this issue and states that retailers have either created new market, to cater for the endless needs and demands internet have brought, or changed existing markets.

The evolution of smart households, or even smart appliances has definitely helped the retail industry to develop to what it is today(Pickett, 2015). Some examples of the smart appliances which are nowadays commonly found in the industry include the 'smart refrigerators', 'smart water heater' and others. As Pickett (2015) states "More and more appliances will be connected and have smart features. The consumer will have greater control and flexibility with the appliance. Appliance to appliance communication will occur to make them run better." this might enable the retail industry to further develop in the near future.

\section{RFID IN RETAIL}

Radio Frequency Identification (RFID), according to Novotny, David and Csafor (2015), is a technology which involves a connected micro-chip with a miniature antenna in which through waves data will be transmitted from the transponder to the interrogator (Chawla and Ha, 2007). This is what makes up a RFID tag, which might be used within the retail industry as it easy to be placed onto different objects as well as being economical to the organisation. According to Novotny, David and Csafor (2015)it is of importance that RFID offers a healthy amount of return of investment to the retailers and therefore would be a possible technology which might be used within the retailing industry. RFID has great potential in which it could generate an extra $2-7$ percent increase in revenue, with a $2-5$ percent reduction in operating expenses, and thus result in a 200 percent ROI $\mathrm{f}$ or a typical manufacturing, warehousing and retailing firm".Novotny, David and Csafor (2015). This shows how RFID can be an important tool within the industry if it is exploited correctly and within the best possible way to help the retail industry grow even more. Therefore RFID has many different ways of applications which can help the retail industry to boost further, through for example quality and efficiency of a service which creates superior customer value (Kotler, 2017). These applications brings about multiple benefits, as discussed by Zare Mehrjerdi (2011)such as human capital in which the use of this technology will aid the retailers by reducing the costs incurred by human capital such as training cost and salary. Some other RFID benefits discussed in the paper "RFID and its benefits: a multiple case analysis" by Zare Mehrjerdi (2011) included self-checkout automation which might help the customer value due to having the possibility to check-out at ones own pace, as well as insight and velocity which go hand in hand together as the valuable data which is collected and produced with the technology will be available in a more efficient manner. Another major benefit for retailers discussed is the opportunity to increase revenue through various factors such as a reduction of out-of stock products, which makes the technology also adaptable for stock and inventory management, in which these benefits alongside other benefits will have the opportunity to develop a better retail industry.

\section{NFC IN RETAIL}

Near Field Communication (NFC), is an evolving technology which facilitates communication between two different nodes or gadgets with a distance of about $20 \mathrm{~cm}$, in which this technology may be embedded within different gadgets such as smart-phones as well as payment devices(Want, 2011). This technology may be useful within the retail industry as it may have many multiple different uses, although it also offers some disadvantages which comes with the technology such as security issues, although this may be improved with the improvement of the technology itself in the future. In 


\section{EPRA International Journal of Research and Development (IJRD)}

the paper 'Near Field Communication', Curran, Millar and Mc Garvey (2012) sees how NFC is "perhaps only a matter of time before NFC becomes another "must have" feature for mobile devices."

According to Curran, Millar and Mc Garvey (2012) it was Barclaycard which has introduced the first form of contactless payment in the U.K. with the maximum transaction value being that of $£ 10$ in the year 2007, by which in 2010 it was increased to $£ 15$. On 3rd August 2017 (BOV, 2017). BOV, one of the most prominent banks in Malta announced that it was also introducing contactless payments capped at $£ 20$, which is nowadays active. Also according Curran, Millar and Mc Garvey (2012) there are other forms of how the NFC technology may be used to aid the contactless payment facilities, with the introduction of NFC technology in smartphones in which the technology aided for the mobile payment to be created, which was adopted by both Google and Apple, two major smart phone producers, in which they where able to create Google Wallet and the Apple Pay respectively. These applications make use of the NFC technology embedded in smart phones to function correctly and efficiently.

Some other type of applications where NFC technology are those which can be used in conjunction with products, or posters to enable more information, this could be through the use of barcodes in which one can use the NFC found on smart phones to enable this process. Another application which one may be used in the airport retail industry is to facilitate the boarding process which tends to be ambiguous, in which NFC boarding passes are issued and then used with an NFC reader to confirm. This was being tested out by Air France-KLM in the France(Mena Report, 2014).

According to Coulombe(2012)NFC can have many different drawbacks, which might impact the use of NFC in the retail industry, some of which include an attack on the confidentiality and integrity of data as well as man-in-the-middle attack which may be of huge cost for the investors in the retail industry if not protected correctly.

\section{INTERNET OF THINGS - CONVENIENCE VS PRIVACY ISSUES}

Internet of things is relatively a new subject for a substantial amount of people. In a study, it was found that although consumer awareness about the subject is low, the interest regarding Internet of Things is high, particularly when it comes to solutions that learn about users' preferences and their behaviour(Newswire, 2015). In addition to this, it was found that in order to drive awareness and adaption there need to be an increase in education in the subject. The idea that Internet of Things makes consumer life easier and more convenient is appealing for both customers and retailers.

\section{Convenience}

Convenience in terms of Internet of Things can be defined as "the extent to which one can control an IOT system at any time and at anywhere through wireless of mobile phone or PC" (Dong et al., 2017).Dong et al. (2017) and Hsu and Lin (2016) states that Internet of Things applications brings convenience to both consumers and retailers as it improves living quality as well as reduces workload. Chang, Dong and Sun(2014) also have their views on the subject. They referred to convenience as the degree to which consumers spend less time in the process of purchasing a product. In addition to this, they also state that convenience will have a positive impact on both consumers' functional and emotional experience. Internet of Things offers convenience for both retailers and consumers. One of the main purposes of devices that form the Internet of Things is to collect data (Rowson, 2016). The collection of data allows for real-time decision making for retailers and actions to be acted upon (Weinberg et al., 2015).

\section{Privacy Issues}

Before we start to discuss privacy issues found in Internet of Things, it is essential to understand the term privacyin terms of Internet of Things.Zhou and Piramuthu (2015)clearly explains the term privacy as a "double-edged sword". On one side people use privacy controls in order to protect their personal information.On the other side we see privacy as a barrier to new Information Technology innovations, such as Internet of Things. Internet of things exist because of data, data about consumers that is passed from a machine to another, therefore consumers' privacy must be at the heart of Internet of Things (Weinberg et al., 2015).

Atkinson (2015) argues that while many literature is currently focusing on the proliferation of connected devices and how they will affect people's lives, there still remain concerns in regards to privacy and security. Hacking goes hand-in-hand with privacy issues. Weinberg et al. (2015)discusses that a security breach could be costly and disastrous for retailers. On the other hand, from consumers' point of view, hacking can also be identity theft and the results can also be disastrous. In his article, Weber(2015) states that a "high-degree of reliability is needed" and systems must be resilient to attacks, data must be authenticated, the need of access control and client privacy.

\section{TECHNOLOGY OF IoT}

The IoT is composed of different devices and attributes connected over an internet connection, therefore having an IP address. This results that the IoT may be divided into three different areas, which all link up together, which are: the Technological Environment, the Physical Environment and the 


\section{EPRA International Journal of Research and Development (IJRD)}

Socio-Economic Environment(Krotov, 2017). All of these areas are then further subdivided into different components which together make up an effective IoT.

The technological environment can be subdivided into hardware, software, network, integrated platforms, standards and data. The hardware include the different devices and components which one may use, such as smartphones, RFID tags, beacons and others in which they will be enabled with communication to create an integrated approach of the IoT. Software includes the IoT applications which are needed in order to support the execution. The network includes the wireless communication between the nodes and internet which are needed for the IoT to function effectively. Having an integrated platform is also ideal for a wellfunctioning IoT, this is because it enables seamless interoperability between the different hardware, software and other components. The standards of the IoT are described as the different technical and operational standards and protocols which are needed to ensure interoperability between the different components. Data is the crucial factor which makes the IoT function as a whole. Data is everywhere, therefore it needs exploitation, where the rest of the technological environment plays the role of the tools for exploitation (Krotov, 2017).

The physical environment can be subdivided into human objects, non-human objects and physical surroundings. The human objects are the human elements who interact with the various components, such as RFID tags, smart phones and others. The non-human objects are the objects which can connect and use a network or connection to transfer data within the IoT. The physical surroundings can be described as both the physical space and the physical substance. The physical space is the space in which the IoT take place, such as the room or building, on the other hand the physical substances may include air and water amongst others, in which the human and non-human objects interact (Krotov, 2017).

The socio-economic environment can be subdivided into consumers, legislative bodies, industry associations, consumers privacy group, entrepreneurs. The consumers are the targeted individuals and organisations which are impacted by the IoT applications. The legislative bodies are the organisations which set and implement laws and regulations regarding the IoT. The industry associations are the personnel whom are creating and maintaining the standards within an IoT connectivity approach. The consumer privacy groups are the individuals and organisation which their primary aim is to protect the consumers from security and privacy violations. Entrepreneurs include the investors who are willing to invest in an IoT application (Krotov, 2017).
In the IoT ecosystem it is important to have a good architecture and design in order for the technology to function effectively. There are four main C's, which are the Categorization, Calibration, Control and Collection(Srivastava, 2015). Categorization may be defined as the ability to classify the objects which are needed in the IoT such as settings, data, application and others. This element can be also used in the other components of calibration, control and collection. Calibration is the ability to adjust according to the various needs of the IoT such as the signalling and also the data within the IoT, in order to achieve the best of the technology which is available. Control is the availability to control the devices which are connected with the IoT, both physically and also virtually, therefore linking more with the other C's of a good IoT architecture. Collection is crucial when developing a successful IoT application where it can successfully pass data to the receivers while also being able to get the data which is needed to be sent. The IoT technology is being vastly used in the retail industry nowadays, and has numerous of functionalities which include: improving the customer experiences in which in-store experiences are shifting to digital experiences, ability to optimize supply chain operations(De Marco et al., 2012) in order to make up to the increasing demands of the consumers, and creating new channels and revenue streams to further improve the organization.

\section{Features}

IoT offer a variety of features for retailers. The simple concept of IoT to link simple things together and constantly collects information. This fact leads to two feature of Internet of things; Intelligence and connectivity. Simple Things are connected together and are becoming increasingly intelligent (Chang, Dong and Sun, 2014). The information collected can be about the physical dimensions such as temperature, customer's' movement within the store and consumption to name just a few. Such information will help retailers to optimize product placement, to better meet and satisfy customer expectations and enhance their instore experience. IoT and the things mentioned above couldn't exist without smart sensors. Their growing use is already affecting and transforming how retailers are implement IoT. Moreover, such feature is offering more connectivity as well as analytics to retailers. In addition, expressing is also another important feature of IoT as it enables connectivity between people and the physical world. It also acts as a mean for retailers to create goods and services that interact intelligently with the real world.

Devices that make up IoT are based on a number of different hardware platforms and 


\section{EPRA International Journal of Research and Development (IJRD)}

networks. This fact leads to another feature of IoT, which is heterogeneity. Devices are heterogeneous in the sense that they can interact and communicate with other devices platforms through different networks. Additionally, another feature is that IoT are dynamic in their nature. IoT' primary activity is to collect data from its environment and this can be done by the dynamic changes occurring around the devices.

\section{Benefits}

IoT can benefit retailers by "enhancing data collection, enabling real-time responses, improving access and control of devices, increasing efficiency and productivity, and connecting technologies" (Weinberg et al., 2015). A challenging aspect that retailers are continuously facing is finding the most profitable customers and giving the deserved special attention to their most important customers. IoT can benefit retailers as it can enhance data collection, thus enabling retailers to make proper customer segmentation and provide personalized offers and promotions to their customers. With the use of RFID chips, sensors and bluetooth beacons retailers can collect data regarding the interaction of customers with store items. Machine learning solutions are then used to push extra information as well as recommendations and special offers on smart displays that can be found within the store.

Retailers are often faced with lack of accurate inventory tracking. Such problems include items placed in incorrect shelves resulting in sales assistants not being able to locate the items customers are looking. This factor might also results in retailers making excessive orders in order to avoid stock outs leading to higher inventory costs and missed sales opportunities(Tan and Karabati, 2013). IoT can be used to tackle such problems as it offers more control and more visibility on inventory items. By creating an inventory management system with the use of RFID chips, sensors and bluetooth beacons, inventory items can be directly connected with database servers. This benefits retailers as they get a clearer picture on the items located at store shelves as well as ensuring that inventory is adequately stocked and reordering items based on the analytics made.

An ever-present challenge that retailers often face is shrinking and fraud from both customers and employees. In order to paint a clearer picture of what takes place in store, retailers can opt for and IoT solution by adding a layer of visibility to inventory items. By using RFIDs and camera feeds in line with machine learning technology, retailers can detect any suspicious movements that might take place in-store. Moreover, such system will discourage anyone who try to obtain items using illegal means as they will be easily detected when compared with traditional systems that used to rely mainly on human monitoring.

Another benefit that IoT offer to retailer is that retailers gather precise information regarding their customers movement patterns throughout the store. Such information can then be used to better layout their stores in order to increase product exposure. In addition to this, IoT solutions offer retailers a potential shift from the traditional methods when it comes to optimize the use of in-store staff. Sales assistants can only watch so many customers at once resulting in missed sales opportunities. Facial expression recognition algorithms are used to identify whether a customer has been standing too long in the same location and can notify a sales-assistant. Such system can benefit both customers and retailers; customers are getting a better service and retailers are optimizing their staff.

\section{Applications}

"The IoT presents an opportunity for retailers to develop a vastly improved ecosystem that connects physical and digital worlds, allowing bidirectional, real-time interaction with consumers both inside and outside the store." (Gregory, 2015). The amount of data produce by such interactions can help retailers to improve customers' in-store experiences. Such data can be collected in various ways. Using bluetooth beacons can help retailers and sales associates to deliver a high-touch service as these serve up information on regular customers, such as their purchase history and preferences. Another application is the use of sensors. Sensors are used to track customers' movements though out the store. The information collected from sensors can help managers to better layout their stores and place their premium products in high traffic areas. A large retail industry which makes use of such application is Hugo Boss. Other applications that can be used by retailers are smart shelves, smart price tags, smart shopping carts, smart phone applications and contact less payment to name just a few(Gregory, 2015).

\section{Limitations}

As highlighted in the previous sections, IoT offer retailers a number of benefits and opportunities to better identify and satisfy customer needs and to expand their market share. However, the effect may be great. Since IoT is a diverse and complex system, any failure that might occur in the software or hardware will have negative and serious implications and consequences on the whole system. In addition to this, even a power cut might cause a lot of inconvenience for retailers who are fully depending on technology. This may results in higher costs as retailers will try to decrease the chance of such events happening by investing in more machinery. Two limitations that we came across in several 


\section{EPRA International Journal of Research and Development (IJRD)}

literature are safety and security. Weinberg et al. (2015) argues that "privacy and security are arguably the most prominent issues; they are at the heart of trust, relationship building, and exchange." The increase in the amount of data and databases in such complex systems like IoT the effects can be great (Weinberg et al., 2015). Complex systems like IoT might be a subject for hacking and exposition of highly sensitive information about the customers. On the other hand, since IoT might be a new concept for consumers, they may not feel safe since new data, such as their shopping patterns and their tastes, is being collected every day.

Without any doubt, technology has revolutionized the way we live. Our lives is becoming controlled by technology. It is our part to decide how much of our daily activities we are willing to mechanize and be controlled by technology. This leads to a limitation which is not affecting retailers specifically, but society as a whole is the issue of employment. Without a doubt, IoT benefitted large industries as it increase productivity with the automation of daily activities. However, the unskilled workers may end up losing their jobs. With the automation of daily activities, there will be fewer requirements from large industries.

\section{Future Perspective}

As noted in Gartner's IT Hype Cycle, IoT has been identified as one of the emerging technologies in Information Technology (Vyas, Bhatt and Jha, 2016). Vyas, Bhatt and Jha(2016)describes a hype cycle as a "way to represent the emergence, adoption, maturity and impact on applications of specific technologies".It has been forecasted that it will take IoT five to ten years to adapt in market and bring retailers cost efficient solutions. Moreover, IoT in retail is just getting started. It has been estimated that by 2020 there will be 4 billion connected people, $\$ 4$ trillion in revenue opportunities, over 25 billion of embedded and intelligent systems and over 50 trillion gigabytes of data.

\section{Google Trends}

\section{Internet of Things}

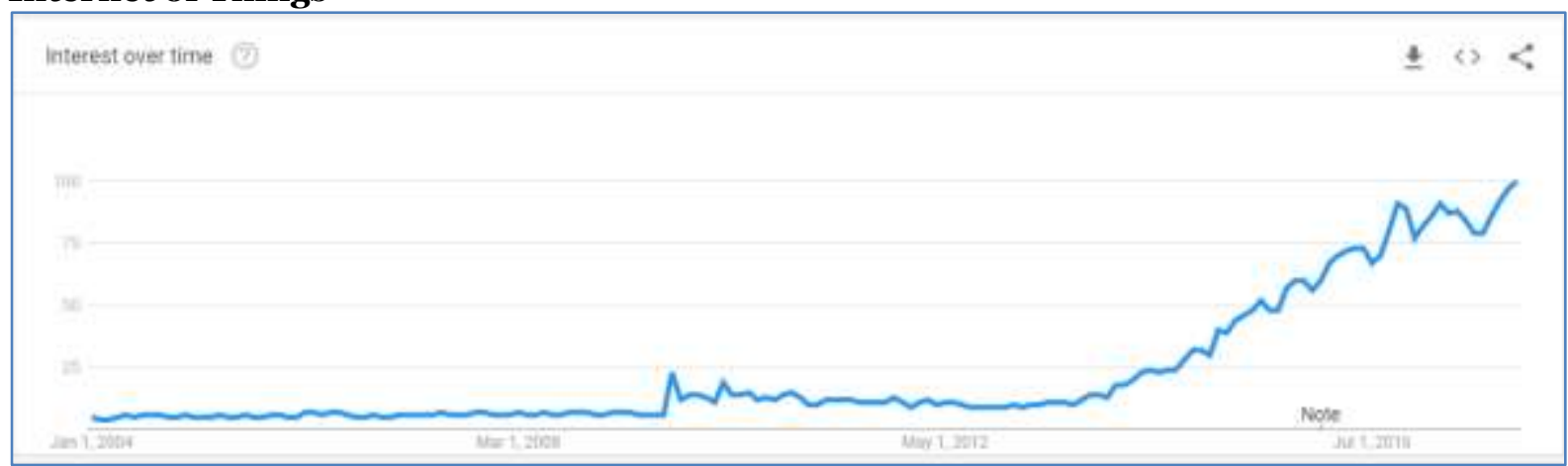

The above screenshot shows the increase in searches on Internet of Things from 2004 onwards, mainly increasing from 2014 till now.

\section{Internet of Things in Retail}

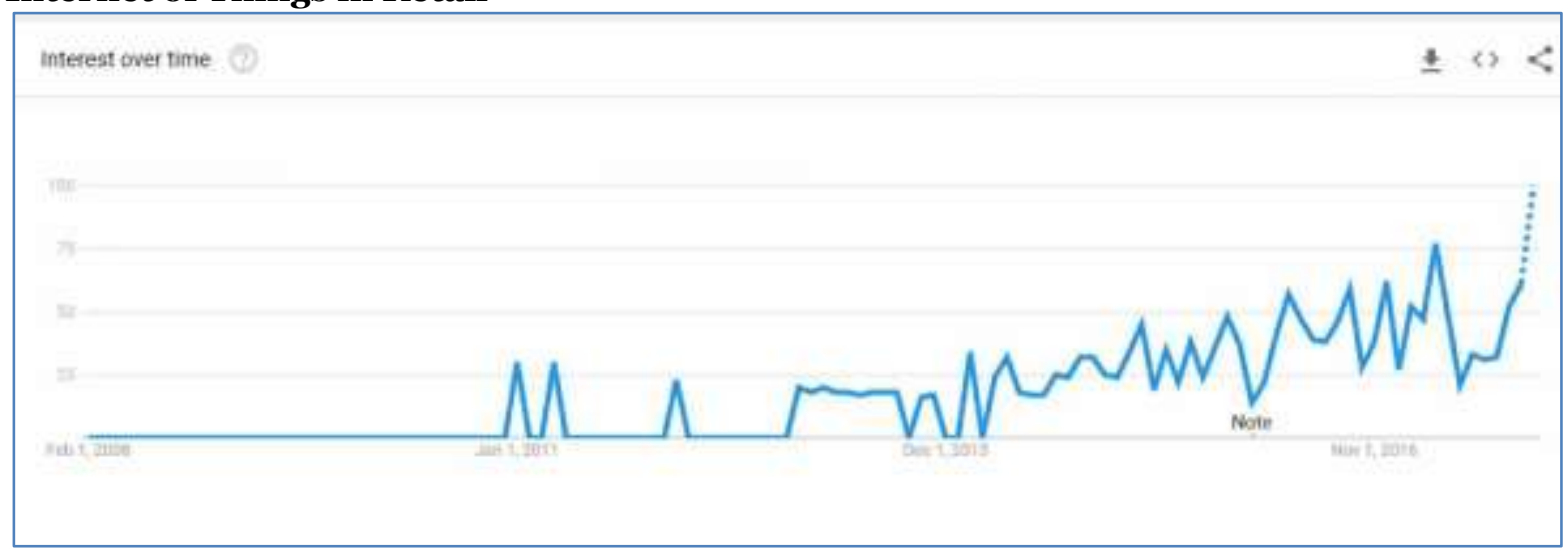


The above screenshot shows the increase in searches on Internet of Things in Retail from 2008 onwards.

\section{REFERENCES}

1. Damian Ryan, Calvin Jones, “Understanding Digital Marketing- Marketing strategies for engaging the digital generation", London, Philadelphia, Kogan Page Ltd., 2009

2. Hanieh Mirzaei, Ehsan Jaryani, Mohammadreza Aghaei, Mehrdad Salehi, Mojtaba Saeidinia, 'Differences of 'Traditional Marketing' in opposition to 'Electronic Marketing',', International Conference on Economics, Business and Marketing Management IPEDR vol.29, 2012

3. Ahmad Roumieh, Lalit Garg "E-Marketing Strategies Exploiting Social Media for Islamic Banking”, International Journal of Emerging Technology and Advanced Engineering,vol 4, Issue 2, 2014.

4. Dave Evans, Jake McKee, "Social Media Marketing- The next generation of business", Wiley Publishing, Inc., 2010

5. Failte Ireland, "Overview of internet marketing”, National tourism Development Authority, 2012

6. Rob Stokes, "EMarketing- the essential guide to digital marketing”, Quirk Ltd., 2011

7. Michael E. Porter. "The Five Competitive Forces that Shape Strategy", Harvard Business Review, January 2008, p.86-104.

8. Siamak Azadi, Elham Rahimzadeh, "Developing marketing strategy for electronic business by using McCarthy's four marketing mix model and Porter's five competitive forces", Emerging Marketing Journal, University Library System of the University of Pittsburgh, 2012.

9. Harvard Business Essentials. "Strategy: Create and implement the best strategy for your business", Boston: Harvard Business School Press, 2005

10. Terry Hill, Roy Westbrook, "SWOT analysis: it's time for a product recall. Long range planning". February 28, Vol. 30, Issue 1, 1997 p.46-52.

11. Hyken "Changing cutomers in modern times", University of London International Programmes, $\underline{2014}$

12. Lashbrooke, "Forcing changing upon businesses", Elsevier Ltd., 2014

13. Chang, Dong and Sun, "Customers perceptual and emotional responses", NJ, USA, Prentice Hall, 2015, p423

14. [14] Gregory, "Digital experiences in marketing", Lahti University of Applied Sciences, 2015 